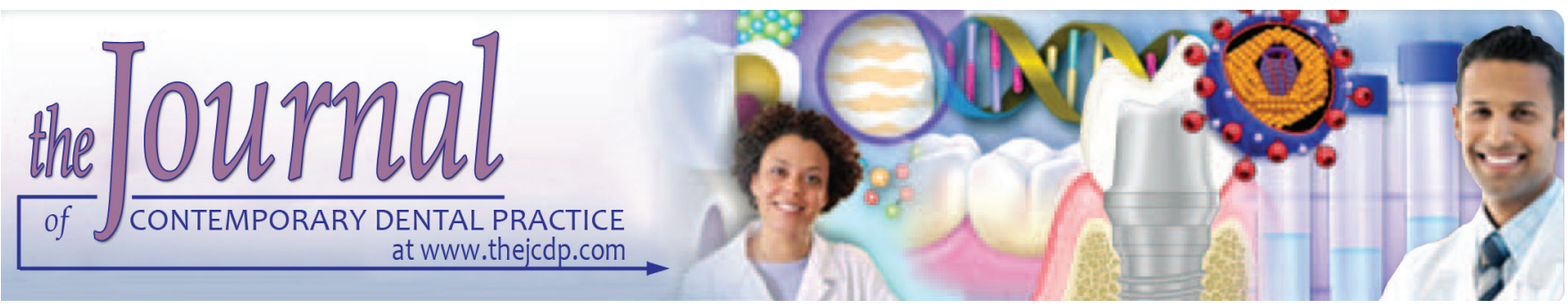

\title{
Knowledge, Attitude, and Practices regarding Pharmacovigilance and Adverse Drug Reaction reporting among Dental Students in a Teaching Hospital, Jodhpur, India: A Cross-sectional Study
}

\author{
${ }^{1}$ Kumar G Chhabra, ${ }^{2}$ Ashish Sharma, ${ }^{3}$ Chaya Chhabra, ${ }^{4} \mathrm{~J}$ Jyothirmai Reddy, ${ }^{5}$ Shravani G Deolia, ${ }^{6}$ Yogesh Mittal
}

\begin{abstract}
Introduction: This is a cross-sectional knowledge, attitude, and practices (KAPs) study on pharmacovigilance (PV) and adverse drug reaction (ADR) reporting among dental students in a teaching hospital in India.
\end{abstract}

Aim: The aim of this study was to assess the KAP of dental students regarding PV, ADR reporting, and barriers toward the same.

Materials and methods: A cross-sectional survey using a selfadministered, investigator-developed, close-ended questionnaire was conducted in an academic dental hospital in India. All prescribers including third year students, final year students, and house surgeons of the same institute were included for assessment of KAP regarding PV using 16, 8, and 8 items respectively. Data regarding barriers toward ADR reporting and demographics were also collected. Mann-Whitney U-test and Kruskal-Wallis test were applied followed by post hoc test.

Results: A total of 241 of 275 respondents participated in the study with a response rate of $87.5 \%$. Overall, $64 \%$ reported that they had no idea about the term PV. Age was significantly associated with knowledge $(p=0.045)$ and attitude $(p=0.016)$. Barriers contributing to underreporting were difficulty in deciding whether or not an ADR has occurred (52.0\%), concerns that the report may be wrong (37\%), lack of confidence to discuss ADR with colleagues $(29 \%)$, and almost no financial benefits (24\%).

\footnotetext{
1,2,4 Department of Public Health Dentistry, Jodhpur Dental College General Hospital, Jodhpur, Rajasthan, India

${ }^{3}$ Department of Pedodontics and Preventive Dentistry, Jodhpur Dental College General Hospital, Jodhpur, Rajasthan, India

${ }^{5}$ Department of Public Health Dentistry, Sharad Panwar Dental College and Hospital, Wardha, Maharasthra, India

${ }^{6}$ Department of Oral and Maxillofacial Surgery, Jodhpur Dental College General Hospital, Jodhpur, Rajasthan, India

Corresponding Author: Kumar G Chhabra, Department of Public Health Dentistry, Jodhpur Dental College General Hospital, Jodhpur, Rajasthan, India, e-mail: rajsushil.chhabra@ gmail.com
}

Conclusion: Participants had a comparatively favorable attitude toward PV, but their knowledge and practice need considerable improvements. This study highlights the need for appropriate dental curriculum changes and further multicentric studies to shed more light on important issues of PV among dentists in India.

Clinical significance: This study explores dentists' knowledge, attitude, and behavior regarding PV, which could help to improve patient's safety and care. The favorable attitude of dentists is an indication that PV could be added in depth in the curriculum and in general practice. Information on barriers for reporting the ADRs could help to find possible solutions for removing the barriers precisely.

Keywords: Adverse drug reactions, Dentists, Knowledge, Pharmacovigilance.

How to cite this article: Chhabra KG, Sharma A, Chhabra C, Reddy JJ, Deolia SG, Mittal Y. Knowledge, Attitude, and Practices regarding Pharmacovigilance and Adverse Drug Reaction reporting among Dental Students in a Teaching Hospital, Jodhpur, India: A Cross-sectional Study. J Contemp Dent Pract 2017;18(10):964-969.

Source of support: Nil

Conflict of interest: None

\section{INTRODUCTION}

Medications have saved the life of many and will continue to do so, but no drug is free from side effects. It may be difficult to rule out that the adverse drug reactions (ADRs) are the common cause of illness, discomfort, disability, and even death with the use of conventional and modern medicines. ${ }^{1,2}$

The World Health Organization (WHO) defines that ADRs are noxious and unwanted effects produced by the drug when it is applied for the ailment of disease or diagnosis. ${ }^{3}$ The hard-hit populations because of ADRs are children, pregnant women, elderly, and the 
diseased. Adequate information regarding drug safety and adverse effects should be conveyed to this vulnerable population through PV programs run on the specific drug. 4

A medicine's side effect is usually rare as its frequency of occurrence is $<0.01 \%$ or 1 in 10,000 , and these side effects cannot be captured from phase I to III clinical trials. Most of the clinical trials rarely involve 10,000 volunteers. Many side effects can be detected only when the drug is in the market and involve a number of patients. ${ }^{5}$ Hence, ADR is a public health problem and the probable solution is reporting of ADRs, PV being the right platform for the same. The WHO defines PV as "the science and activities relating to the detection, assessment, understanding and prevention of adverse effects or any other medicine-related problem". 6 To strengthen the adverse drug reporting, ADR monitoring centers are being set up in various parts of India as PV Program of India (PvPI), and its headquarter is situated at Ghaziabad, Uttar Pradesh, India. ${ }^{7}$ Despite the call from WHO to strengthen the national PV system and to make it an integral part of health care delivery system, developing countries are still fumbling.

A study conducted by Ramesh et $\mathrm{al}^{8}$ in South India observed that $0.7 \%$ of hospital admissions were due to ADRs and a total of $3.7 \%$ of the hospitalized patients experienced an ADR, of which 1.3\% were fatal. Another study by Arulmani et $\mathrm{al}^{9}$ concluded that ADRs were responsible for $3.4 \%$ of hospital admissions. The incidence of serious ADRs in India was reported to be $6.7 \%{ }^{7}$

The profession of dentistry is a significant part of health care delivery system of India and enjoys sovereignty. Pharmacotherapy plays a noteworthy role in the treatment and management of oral diseases, such as dental abscess, periodontal diseases, opportunistic infections in oral cancer patients, prophylactic doses of drugs before invasive procedures, and many more. The oral pharmaceutical paraphernalia is widening its scope day by day in terms of use of conventional and modern drugs and combination of various drugs. Dentists are involved in prescribing many antibiotics, analgesics, and anti-inflammatory drugs and remedial interventions like application of local anesthesia for many dental procedures. The risk of ADR cannot be overlooked in dentistry and dentists can be a vital source in reporting ADRs as they are equally distributed as that of medical professionals in the health care sector in the Indian scenario. Many studies reported in the literature have assessed the KAPs regarding underreporting and PV among medical professionals, ${ }^{10-13}$ but there is a severe dearth of information, which investigated the same, among dental professionals in India.
Therefore, this study intended to evaluate the KAP of dentists to ADR reporting in a dental teaching hospital and to explore the barriers in reporting of ADR through questionnaire method.

\section{MATERIALS AND METHODS}

A cross-sectional, questionnaire-based survey was conducted among the students of third year, final year, and house surgeons of Jodhpur Dental College General Hospital, Jodhpur, Rajasthan, India. A list of all third and fourth year students and house surgeons was obtained from the administrative office of the institution. Prior approval to conduct the study was obtained from the ethical committee of the institutional review board.

A close-ended, self-administered questionnaire was developed by the investigators. It elicited KAP of the study subjects regarding PV and the factors discouraging reporting of ADRs. The item generation for this instrument was from four sources: Theory, research, observation, and expert opinion. The questionnaire was pretested in 35 postgraduate students before the start of the main study; a suitably modified version was finally administered to the willing respondents. Cronbach's alpha and split-half reliability values were 0.72 and 0.69 for knowledge; 0.86 and 0.74 for attitude; and 0.88 and 0.91 for practice respectively.

A total of 16,8 , and 8 items assessed respondent's KAP respectively, and the factors that discouraged reporting. The attitude was assessed using a 5-point Likert scale: Definitely yes, yes, neutral, no, and definitely no. The response options for items assessing practice were $<1$ month, 1 to 6 months, 6 to 12 months, more than 1 year, and never. The correct answer for knowledge was given a score of 1 and wrong answers or not attempted was scored as 0 . Attitude scores ranged from 5 (definitely yes) to 1 (definitely no), and practice scores ranged from 5 ( 1 month) to 1 (never). A score $\geq 80 \%$ of the possible maximum scores was considered as good, between 60 and $79 \%$ as fair, and $<60 \%$ as poor.

Demographic information, such as age, gender, and qualification was also obtained. Differences in the median scores were compared based on age, gender, and qualification. Along with this, factors that discouraged the reporting of ADRs were also assessed, such as lack of knowledge to report, lack of time to fill the form and report, lack of financial benefits, and disinterest in reporting and legal complications associated with reporting of ADRs.

The third year students, fourth year students, and the house surgeons were assembled in a lecture hall and were explained about the purpose of the questionnaire 
survey, followed by instructions for filling in the questionnaire. Subsequent to this, a packet consisting of informed consent, instructions, and a questionnaire was handed over to them by the investigators, and the students were given 1 hour to complete and return the questionnaire. Those who were not willing to participate or did not return the questionnaire within the stipulated time were excluded from the study.

A total of 16 questions on PV focused on what all health care providers can report ADR, some recently banned drugs because of PV, where all WHO collaborating centers are located to provide technical assistance for PV, indicators for efficient working of PV, and various PV methods. Questions related to attitude included whether dentists should be actively involved in PV activities, if they should act in coordination with other professionals toward PV, if they should constantly update their knowledge on PV, and if there should be continuing dental education programs on PV for dentists. Questions pertinent to practice assessed how frequently the respondents perused scientific journals and the Internet regarding PV, if they maintained accurate patient records, and if they attended training programs regarding $\mathrm{PV}$

\section{Statistical Analysis}

The data were entered into a Microsoft Excel spreadsheet version 12.0 (Microsoft, Redmond, Washington USA); Statistical Package for the Social Sciences version 16.0 (IBM, Armonk, New York, USA) was used for statistical analysis. Student's $t$-test was applied to determine the relationship between the median total scores and demographic variables and relationship between median scores of KAP and demographic variables. Mann-Whitney U-test and Kruskal-Wallis test were applied followed by post hoc test. Descriptive analysis was applied to determine perceived barriers for reporting ADRs among the respondents.

\section{RESULTS}

Table 1 shows that total median KAP score of the patients was moderate. The total median knowledge score was poor, total median attitude score was good, and total practice score was also poor.

Table 2 shows the relationship between demographic characteristics of respondents and median total scores [interquartile range (IQR)] of KAP on ADR reporting, which shows that median total score [58 (13)] was significantly $(\mathrm{p}=0.05)$ higher among study participants with age more than 25 years. In relationship to qualification, median total score was significantly $(\mathrm{p}=0.000)$ higher among third year students [61 (6)] than final year students [49 (9)] and house surgeons [60 (6)].

Table 3 shows relationship between the demographic characteristic of study participants and median KAP

Table 1: The range of scores, medians, and IQR obtained for the study participants in terms of total KAP

\begin{tabular}{llll}
\hline & Range & Median & IQR \\
\hline Total KAP score & $33-76$ & 58 & 11 \\
Total knowledge score & $0-14$ & 6 & 4 \\
Total attitude score & $18-40$ & 35 & 3 \\
Total practice score & $2-32$ & 18 & 12 \\
\hline
\end{tabular}

Table 2: Demographics of respondents and relationship between the median total score

\begin{tabular}{llll}
\hline $\begin{array}{l}\text { Demographic } \\
\text { variables }\end{array}$ & Number (\%) & $\begin{array}{l}\text { Median total } \\
\text { score }(\text { IQR) }\end{array}$ & p-value \\
\hline $\begin{array}{l}\text { Gender } \\
\text { Male }\end{array}$ & $83(34.4)$ & $59(10)$ & 0.082 \\
$\quad$ Female & $158(65.6)$ & $58(12)$ & \\
Age group & & & \\
$\quad<25$ years & $197(81.7)$ & $58(13)$ & $0.009^{* *}$ \\
$>25$ years & $44(18.3)$ & $60(6)$ & \\
Qualification & & & \\
Third year & $76(31.5)$ & $61(6)$ & \\
Final year & $78(32.4)$ & $49(9)$ & \\
Internship & $87(36.1)$ & $60(6)$ & \\
\hline *p $\leq 0.05,{ }^{* *} \mathrm{p} \leq 0.01,{ }^{* * *} \mathrm{p} \leq 0.000$ & &
\end{tabular}

Table 3: Demographics of respondents and relationship between median KAP score

\begin{tabular}{|c|c|c|c|c|c|c|}
\hline $\begin{array}{l}\text { Demographic } \\
\text { variables }\end{array}$ & $\begin{array}{l}\text { Median knowledge } \\
\text { score (IQR) }\end{array}$ & $p$-value & $\begin{array}{l}\text { Median attitude } \\
\text { score (IQR) }\end{array}$ & $p$-value & $\begin{array}{l}\text { Median practice } \\
(I Q R)\end{array}$ & $p$-value \\
\hline \multicolumn{7}{|l|}{ Gender } \\
\hline Male & $6(3)$ & 0.547 & $35(3)$ & 0.812 & $19(7)$ & $0.046^{*}$ \\
\hline Female & $6(4)$ & & $35(3)$ & & $17(4)$ & \\
\hline \multicolumn{7}{|l|}{ Age group } \\
\hline$<25$ years & $7(4)$ & $0.000^{* * *}$ & $35(3)$ & 0.358 & $17(12)$ & $0.000^{* * *}$ \\
\hline$>25$ years & $5(2)$ & & $35(3)$ & & $20.5(6)$ & \\
\hline \multicolumn{7}{|l|}{ Qualification } \\
\hline Third year & $7(4)$ & $0.000^{* * *}$ & $34(3)$ & 0.825 & $19.50(5)$ & $0.000^{* * *}$ \\
\hline Final year & $6(4)$ & & $35(4)$ & & $8(5)$ & \\
\hline Internship & $5(2)$ & & $35(3)$ & & $20(6)$ & \\
\hline
\end{tabular}


KAP regarding PV and ADR reporting among Dental Students in a Teaching Hospital, Jodhpur, India

Table 4: Perceived barriers for reporting ADR among house surgeons, third year students, and final year students

\begin{tabular}{|c|c|c|c|c|}
\hline Perceived barriers & $\begin{array}{l}\text { House surgeons } \\
\text { (total = 87) }\end{array}$ & $\begin{array}{l}\text { Final year } \\
\text { (total = 78) }\end{array}$ & $\begin{array}{l}\text { Third year } \\
\text { (total = 76) }\end{array}$ & Total $=241$ \\
\hline Concerns that the report may be wrong & $36(41 \%)$ & $30(39 \%)$ & $23(30 \%)$ & $89(37 \%)$ \\
\hline Difficult to decide whether or not an ADR has occurred & $45(52 \%)$ & $43(55 \%)$ & $37(49 \%)$ & $125(52 \%)$ \\
\hline Lack of time to fill in an ADR form & $32(37 \%)$ & $12(15 \%)$ & $20(26 \%)$ & $64(27 \%)$ \\
\hline Concerns that the report may generate extra work & $27(31 \%)$ & $16(21 \%)$ & $27(36 \%)$ & $70(29 \%)$ \\
\hline Lack of confidence to discuss the ADR with other colleagues & $25(29 \%)$ & $20(26 \%)$ & $30(39 \%)$ & $75(31 \%)$ \\
\hline Almost no financial benefits & $28(32 \%)$ & $21(27 \%)$ & $08(11 \%)$ & $57(24 \%)$ \\
\hline Procrastination and disinterest in reporting of any ADR & $19(22 \%)$ & $22(28 \%)$ & $17(22 \%)$ & $58(24 \%)$ \\
\hline
\end{tabular}

scores (IQR) regarding reporting of ADR, which shows that median practice scores were significantly $(\mathrm{p}=0.046)$ higher among male respondents [19 (7)]. Knowledge of reporting ADR was significantly $(p=0.000)$ better in study participants with age $<25$ [7(4)], while the median practice scores were significantly $(\mathrm{p}=0.000)$ better among study participants aged more than 25 years [20.5 (6)]. Among all study participants, third year students were having significantly $(\mathrm{p}=0.000)$ better knowledge scores [7 (4)] regarding ADR reporting. Median practice score among house surgeons was significant $(\mathrm{p}=0.000)$ and was slightly more than third year students [20 (6)].

Table 4 shows that the majority of study participants in all three categories were facing barriers of difficulty in taking a decision about the occurrence of ADR (52\%). Other barriers in reporting ADR were concerns that the report may be wrong (37\%) and lack of confidence to discuss the ADR with other colleagues (31\%). The least reported barrier was almost no financial benefits [57 $(24 \%)]$.

\section{DISCUSSION}

The present questionnaire-based study conducted among prescribers (third year, final year, and house surgeons) of a tertiary care dental teaching hospital in the western part of Rajasthan, India, explored the KAPs of a dental student regarding PV and barriers regarding reporting of ADRs. Although PV systems have grown in recent times, it is in infancy stage in Indian scenario. India being a rich kaleidoscope of cultural diversity exhibits further problems as along with allopathic drugs, Ayurvedic, Homeopathic, herbal, and Unani drugs are also prescribed; all these may pose different drug-related problems. The PvPI publishes information related to ADRs regularly and a lot of information is presented in the database, ${ }^{14}$ but still there is a lack of studies which address KAPs of dentists toward PV and ADR reporting mechanisms in the country. This study is an effort to explore KAP and perceived barriers for PV activities and reporting of ADRs among dental professionals in Rajasthan, India.

In this study, $34.4 \%$ of the study participants were males and $65.6 \%$ were females. It was observed in the study that overall $64 \%$ of participants do not have any idea regarding the term PV. This can be attributed to unfamiliarity of the study participants to the PvPI or lack in syllabus of the dental curriculum which covers this topic in detail. Similar results have been reported by Khan et $\mathrm{l}^{15}$ and Palaian et $\mathrm{al}^{16}$ among health-care professionals in Nepal and Rajesh et al. ${ }^{17}$

The low objective knowledge scores among dentists in this study were in agreement with the studies done by Khan et al. ${ }^{15}$ Contrasting results have been observed in a

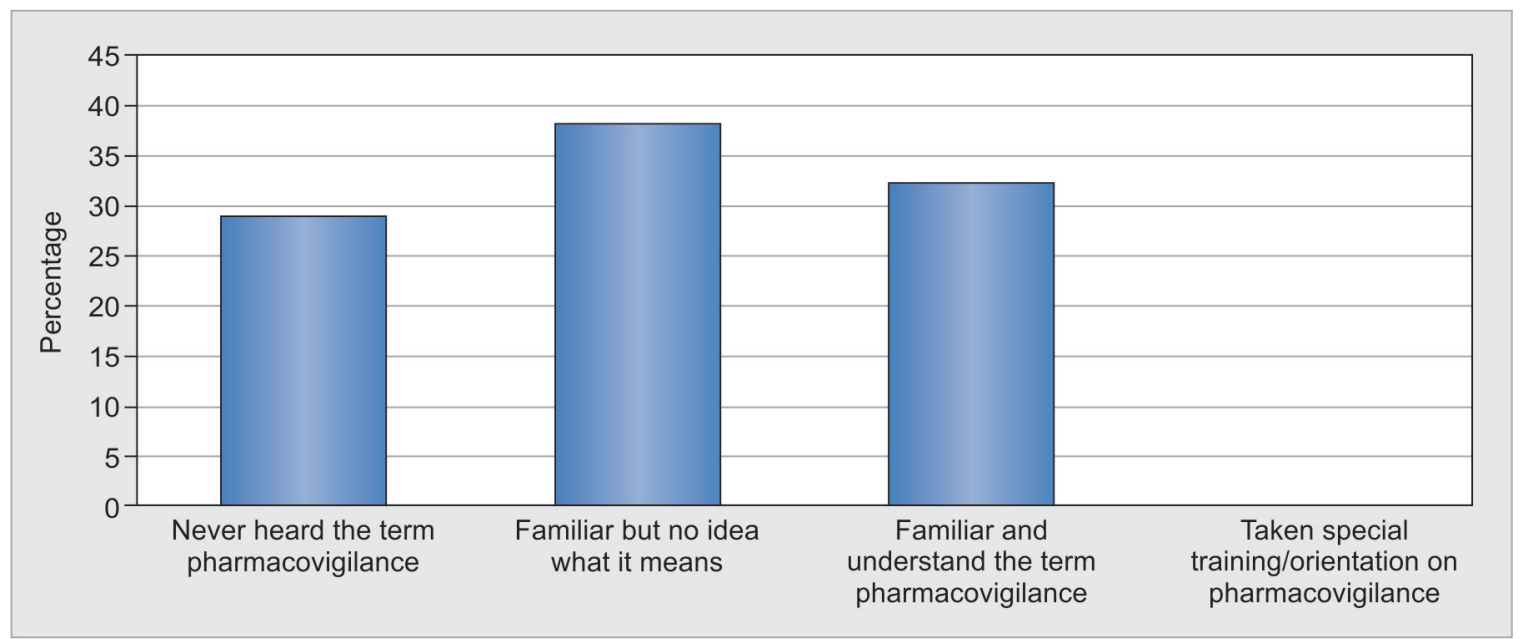

Graph 1: Term PV as understood by study participants 
study performed by dentists in the United Kingdom by Yip et al. ${ }^{18}$ Studies done among medical health professionals of developed countries like the United States and the United Kingdom have shown better knowledge scores. ${ }^{19-21}$ In the United Kingdom and the United States, most of the medical and dental schools have introduced a yellow card ADR reporting system in the undergraduate syllabus and their skills are also assessed. In the studies reported by Desai et $\mathrm{al}^{10}$ and Gupta and Udupa, ${ }^{11}$ only 30 to $90 \%$ of medical professionals in India have been found to be aware of ADR reporting system. In most of the developing nations at large and India specifically, implementation of $\mathrm{PV}$ is at the nascent stage and this could have contributed to low objective knowledge regarding PV. This may affect reporting of ADRs and could be grievous to the patients and society as a whole. Pharmaceutical setup of India is growing very fast, and Indian market is overflowing with newer drugs every day.

Better attitude score among study participants in this study indicates willingness of dentists to make significant contributions toward PV activities in India. A significant difference between attitude scores was not observed among the three different groups. Knowledge and attitude toward PV can be improved by resource-centered educational programs on PV and ADR reporting. The practice of PV can be expected to improve with appropriate attitude.

Low practice scores for PV among study participants can be attributed to the fact that even though during the second year of undergraduation dental students are taught theoretically about the mechanism about ADR reporting, there is no specific mechanism to practice PV-related work on subsequent years of undergraduation or postgraduation tenures.

With increasing age, better practice of PV was observed in the study. A significant difference between practice scores was observed among the study groups, with highest among the third year students. This can be attributed to the fact that they have recently finished second year and studied the subject pharmacology, which might have contributed to the difference.

Intensive monitoring approach in PV can improve the detection of ADRs. ${ }^{22}$ Various approaches have been recommended to intensify reporting, like forming ADR reporting network within the hospital, ${ }^{23}$ encouraging and educating patients to report ${ }^{24}$ and making ADR reporting compulsory for dentists too.

Among the three different academic positions, the overall median KAP scores were highest among the third year students, which can be explained on the basis that they have just finished second year and pharmacology is the part in second year curriculum. In pharmacology, they are taught about ADRs, hence it might have contributed to higher KAP scores. Practice scores among house surgeons were found to be better as compared with final year students; house surgeons might have seen more cases of ADR and could be more cautious about such events.

Participants' sociodemographic information regarding age, gender, and qualification was also obtained, and only age was significantly associated with knowledge and practice. This could be explained on the ground that, with increasing age, dental professionals' experience about PV and ADR increases the knowledge and subsequently improves practice. Similar findings have been reported by Yip et al. ${ }^{18}$

Difficulty in deciding whether an ADR has occurred or not $(52 \%)$ coupled with concerns that the report may be wrong $(37 \%)$ is pinpointing toward the lack of knowledge and training of dentists in terms of identifying ADRs. Analogous findings of 65.5 and $27.5 \%$ were observed in studies done by Khan et al ${ }^{15}$ and $80.9 \%$ and $81.8 \%$ among medical doctors by Gupta and Udupa ${ }^{11}$ respectively. Other reported barriers are a lack of confidence to discuss ADR with colleagues (31\%); reporting may generate extra work $(29 \%)$ and lack of time $(27 \%)$. These problems can be addressed by coordinated and planned integration of professionals like pharmacologists, experienced physicians, and dentists on the topic of PV and reporting of ADRs and with strict implementation of legislative norms regarding reporting of ADRs by the government.

\section{LIMITATIONS}

All cross-sectional questionnaire studies have inbuilt limitations, and this study is no exception. Findings from one dental college may not be fully generalizable. In questionnaire-based studies, there is possibility of social desirability of faking good bias, and/or deviation or negative bias. Likert scales may be associated with biases, such as end-aversion bias, positive skew, and the halo effect. ${ }^{25}$ Specific and appropriate interventions cannot be planned by cross-sectional studies alone, but such studies provide a good platform for future solutions. Further longitudinal and multicentric studies might shed more light on important issues of PV among dentists in India.

\section{CONCLUSION}

In conclusion, this study provides an insight into PV scenario among dental professionals in India. There is an urgent need of inclusion of PV in detail in the dental curriculum not only stressing on theoretical knowledge but also practical implication of the same. All dental graduates should obtain sufficient knowledge and training regarding PV in routine dental prescribing. Faculty should guide the students regarding PV and ensure implementation in every prescription. The comparatively 
favorable attitude of the study participants in the present study can be the key for the success of PV activities among dentists in India.

\section{REFERENCES}

1. Pirmohamed M, James S, Meakin S, Green C, Scott AK, Walley TJ, Farrar K, Park BK, Breckenridge AM. Adverse drug reactions as cause of admission to hospital: prospective analysis of 18820 patients. BMJ 2004 Jul;329(7456):15-19.

2. Lazarou J, Pomeranz BH, Corey PN. Incidence of adverse drug reactions in hospitalized patients: A meta-analysis of prospective studies. JAMA 1998 Apr;279(15):1200-1205.

3. Shuka SS, Gidwani B, Pandey R, Rao SP, Singh V, Vyas A. Importance of pharmacovigilance in Indian pharmaceutical industry - review article. Asian J Res Pharm Sci 2012;2(1):4-8.

4. Santosh KC, Tragulpiankit P. Pharmacovigilance: an overview. Mahidol Univ J Pharm Sci 2011;38(1-2):1-7.

5. Paveliu MS, Bengea-Luculescu S, Toma M, Paveliu SF. Perception on adverse drug reaction reporting by physicians working in Southern Romania. Maedica (Buchar) 2013 Mar;8(1):17-25.

6. World Health Organization. The safety of medicines in public health programmes: pharmacovigilance an essential tool. Geneva: World Health Organization; 2006. [cited 2015 Jul 07]. Available from: http:/ / www.who.int/medicines/areas/ quality_safety/safety_efficacy/pharmacovigilance_B.pdf.

7. Importance of ADR Reporting in India. [cited 2015 Jul 28]. Available from: http:/ / www.pharmacovigilance.co.in.

8. Ramesh M, Pandit J, Parthasarathi G. Adverse drug reactions in a south Indian hospital-their severity and cost involved. Pharmacoepidemiol Drug Saf 2003 Dec;12(8):687-692.

9. Arulmani R, Rajendran SD, Suresh B. Adverse drug reaction monitoring in a secondary care hospital in South India. Br J Clin Pharmacol 2008 Feb;65(2):210-216.

10. Desai CK, Iyer G, Panchal J, Shah S, Dikshit RK. An evaluation of knowledge, attitude, and practice of adverse drug reaction reporting among prescribers at a tertiary care hospital. Perspect Clin Res 2011 Oct;2(4):129-136.

11. Gupta P, Udupa A. Adverse drug reaction reporting and pharmacovigilance: knowledge, attitudes and perceptions amongst resident doctors. J Pharm Sci Res 2011;3(2):1064-1069.

12. Ramesh M, Parthasarathi G. Adverse drug reactions reporting: attitudes and perceptions of medical practitioners. Asian J Pharm Clin Res 2009 Apr-Jun;2(2):10-14.
13. Khan SA, Goyal C, Chandel N, Rafi M. Knowledge, attitudes, and practice of doctors to adverse drug reaction reporting in a teaching hospital in India: an observational study. J Nat Sci Biol Med 2013 Jan;4(1):191-196.

14. Pharmacovigilance Program of India 2010. CDSCO, Ministry of Health and Family Welfare, Government of India. 2010. [cited 2015 May 05]. Available from: http:/ /www.cdsco.nic. in/pharmacovigilance.htm.

15. Khan SA, Goyal C, Tonpay SD. A study of knowledge, attitudes, and practice of dental doctors about adverse drug reaction reporting in a teaching hospital in India. Perspect Clin Res 2015 Jul-Sep;6(3):144-149.

16. Palaian S, Ibrahim MI, Mishra P. Health professionals' knowledge, attitude and practices towards pharmacovigilance in Nepal. Pharm Pract (Granada) 2011 Oct-Dec;9(4):228-235.

17. Rajesh R, Vidyasagar S, Varma DM. An educational intervention to assess knowledge attitude practice of pharmacovigilance among health care professionals in an Indian tertiary care teaching hospital. Int J Pharm Tech Res 2011 Apr-Jun;3(2):678-692.

18. Yip J, Radford DR, Brown D. How do UK dentists deal with adverse drug reaction reporting? Br Dent J 2013 Apr;214(8):E22.

19. Bateman DN, Sanders GL, Rawlins MD. Attitudes to adverse drug reaction reporting in the Northern region. Br J Clin Pharmacol 1992 Nov;34(5):421-426.

20. Milstein JB, Faich GA, Hsu JP. Factors affecting physician reporting of adverse drug reactions. Drug Inf J 1986 Apr;20(2):157-164.

21. Cox AR, Marriott JF, Wilson KA, Ferner RE. Adverse drug reaction teaching in UK undergraduate medical and pharmacy programmes. J Clin Pharm Ther 2004 Feb;29(1):31-35.

22. Khan LM, Al-Harthi SE, Saadah OI. Adverse drug reactions in hospitalized pediatric patients of Saudi Arabian University Hospital and impact of pharmacovigilance in reporting ADR. Saudi Pharm J 2013 Jul;21(3):261-266.

23. Goldstein LH, Berlin M, Saliba W, Elias M, Berkovitch M. Founding an adverse drug reaction (ADR) network: a method for improving doctors spontaneous ADR reporting in a general hospital. J Clin Pharmacol 2013 Nov;53(11):1220-1225.

24. Inch J, Watson MC, Anakwe-Umeh S. Patient versus healthcare professional spontaneous adverse drug reaction reporting: a systematic review. Drug Saf 2012 Oct;35(10):807-818.

25. Streiner, DL.; Norman, GR. Devising the items. In: Streiner DL, Norman GR, editors. Health measurement scales: a practical guide to their development and use. PDQ Statistics. Oxford: Oxford University Press; 1995. p. 15-26. 